PUBLIC HEALTH RESEARCH

\title{
Training is an Important Factor for Community Health Workers in Performing KOSPEN Health Screening Activities in Malaysia: Community Health Workers (KOSPEN) 2016
}

\author{
Tania Gayle Robert Lourdes, ${ }^{+1}$ Wan Shakira Rodzlan Hasani, ${ }^{1}$ Muhammad Fadhli Mohd Yusoff, ${ }^{1}$ Hamizatul \\ Akmal Abd Hamid, ${ }^{1}$ Halizah Mat Rifin,1 Hasimah Ismail, ${ }^{1}$ Thamil Arasu Saminathan, ${ }^{1}$ Jane Ling Miaw Yn, ${ }^{1}$ \\ Nur Liana Ab Majid, ${ }^{1}$ Mohd Ruhaizie Riyadzi, ${ }^{1}$ Ahzairin Ahmad ${ }^{1}$ and Rosnah Ramly ${ }^{2}$ \\ ${ }^{1}$ Institute for Public Health National Institutes of Health (NIH), Ministry of Health Malaysia, No.1, Jalan Setia \\ Murni U13/52, Seksyen U13, Bandar Setia Alam, 40170 Shah Alam, Selangor, Malaysia. \\ ${ }^{2}$ Level 2, Block E3, Disease Control Division, Ministry of Health Malaysia, Pusat Pentadbiran Kerajaan \\ Persekutuan, 62590 Putrajaya, Malaysia.
}

*For reprint and all correspondence: Tania Gayle Robert Lourdes, Institute for Public Health National Institutes of Health (NIH), Ministry of Health Malaysia, No.1, Jalan Setia Murni U13/52, Seksyen U13, Bandar Setia Alam, 40170 Shah Alam, Selangor, Malaysia.

Email : gayle4886@yahoo.com

ABSTRACT

\begin{tabular}{ll}
\hline Introduction & Community health workers/volunteers (CHW) are health workers who are \\
& trained but do not possess a formal professional certificate. They are members \\
of the community who live and work in that particular community. This study \\
aimed to determine factors associated with not performing health screening \\
activities by volunteers under KOSPEN; a community-based intervention \\
programme, initiated by Ministry of Health Malaysia in October 2013 . \\
Data from the "Evaluation of the implementation of KOSPEN programme in \\
Malaysia 2016" was used,a cross-sectional study which was carried out in \\
randomly selected KOSPEN localities throughout Malaysia. The response rate \\
was $94.9 \%$ A pre-tested, self-administered questionnaire was used. \\
Descriptive statistics andlogistic regression analysis was applied using \\
Statistical Package for Social Sciences (SPSS) version 20. \\
700 volunteers were included in this study. Majority were female (65.7\%), \\
aged 50-59 years (30.9\%), had secondary education (65.3\%), employed \\
(55.7\%.) and married (80.4\%). Several issues were identified by the \\
volunteers; funding (47.2\%), module content and comprehensibility (11.4\% \\
respectively), submitting returns (17\%). Multivariate logistic regression \\
showed that volunteers who never attended training (aOR $2.79 ; 95 \%$ CI:1.66, \\
4.67) and who felt the content of the training module was inadequate (aOR \\
2.693; 95\% CI: 1.46, 4.98) were more likely did not perform screening \\
activities in the community. \\
Volunteers who were not trained and those who felt the content of the training \\
module was inadequate did not carry out screening activities. These findings \\
will be useful for stakeholders to make improvements to the programme for a \\
more successful implementation. \\
KOSPEN - community health workers - NCD screening - community - based \\
intervention \\
Keywords
\end{tabular}

Article history:

Received: 23 March 2021

Accepted: 25 June 2021

Published: 1 September 2021 


\section{INTRODUCTION}

The World Health Organization (WHO) reported that, major non-communicable diseases (NCD) which include cardiovascular diseases, cancer, diabetes and chronic respiratory diseases account for almost $80 \%$ of all deaths in the Western Pacific Region and also $50 \%$ of all premature mortality (under 70 years) in low and middle income countries in the region. ${ }^{1}$ Modifiable behaviours, such as tobacco use, physical inactivity, unhealthy diet and the harmful use of alcohol, all increase the risk of NCDs. ${ }^{2}$ The WHO in their global action plan to combat NCDs have asked to incorporate the prevention and control of noncommunicable diseases in the training of all health personnel including community health workers, social workers, professional and non-professional (technical, vocational) staff, with an emphasis on primary health care. ${ }^{3}$

Community health workers (CHW) or community health volunteers are as health workers who have been trained to some extent but do not possess a formal professional certificate, many live and work in the community. It encompasses a wide range of health workers, paid and unpaid, professional and lay, experienced and inexperienced, including traditional birth attendants, village health workers, peer supporters, community volunteers and health extension workers. ${ }^{3}$

Various studies around the world have pointed towards engaging community health workers or volunteers in addressing the ever-rising threat of NCDs in the community. In a study done in Northern Mexico on a community health worker intervention programme, there were significant decreases from baseline readings of body mass index (BMI), waist circumference, hip circumference, weight, glucose and cholesterol levels. ${ }^{4}$

A systematic review from Nigeria concluded that CHWs have the potential to improve knowledge, health behaviour and health outcomes related to prevention and management of type 2 diabetes (T2DM) in low and middle income countries (LMIC). 5,6 Positive outcomes were reported in 7 of 10 studies. These outcomes included increased knowledge of T2DM symptoms and prevention measures; increased adoption of treatment-seeking and prevention measures; increased medication adherence; and improved fasting blood sugar, glycated hemoglobin, and BMI. $^{5}$

The Global Action Plan for the Prevention and Control of NCDs in Malaysia has several targets put place in the mission to reduce the burden of NCDs. ${ }^{3,7}$ In order to achieve these NCD targets, the Ministry of Health Malaysia had initiated a community-based intervention programme, known as Healthy Community Empowers the Nation or 'Komuniti Sihat Pembina Negara' (KOSPEN) in
October 2013. This intervention programme is a collaborative initiative by the Ministry of Health $(\mathrm{MOH})$ with other government ministries and agencies such as the Department of Community Development (KEMAS) and the Community Watch (Rukun Tetangga or RT) under the Department of National Unity and Integration (JPNIN) which established the KOSPEN-KEMAS and KOSPENRT. The main scopes of KOSPEN include healthy eating, active lifestyle, body weight management, no smoking as well as early detection of NCD risk factors through early screening. The core functioning unit for KOSPEN activities are the KOSPEN volunteers or better known as Pasukan Gerak Sihat Malaysia (GSiM). The main role of the KOSPEN volunteers is to conduct NCD risk factor screening in the community which include height and weight, BMI, abdominal circumference, blood glucose levels and blood pressure measurements. They were also required to demonstrate healthy cooking ways, encourage people to walk 10,000 steps per day and declare smoke free areas. ${ }^{8}$

However, a study done in in Malaysia reported that non-participation of the community in health screening activities conducted by the KOSPEN volunteers was $75 \% .{ }^{9}$ Taking into account all of these factors, this study was initiated to determine the factors associated with not performing health screening activities by KOSPEN volunteers.

\section{METHODOLOGY}

Data used for this study was obtained from the "Evaluation of the implementation of KOSPEN programme in Malaysia 2016", a cross-sectional study which was carried out in randomly selected KOSPEN localities throughout Malaysia from May to June 2016. The target population of this study were the KOSPEN volunteers under the KOSPEN programme in those selected localities. The KOSPEN volunteers were selected based on a few criteria such as preparedness to serve on a voluntary basis, commitment to become a volunteer, aged 18 years old and above, able to read and write, permanent resident of the community served, independent of any political, religious, or personal gains and have an interest in health care. Those who selected were required to undergo 2 days of training based on the KOSPEN training module from the Ministry of Health. A total of 103 localities which had implemented KOSPEN before 01 July 2015 were included in this study. Sample size was calculated using a single proportion formula for estimated prevalence. After adjusting for finite population, design effect and a non-response rate of $20 \%$, the optimum sample size required was 762 . Therefore, the response rate obtained was $94.9 \%$.

Data collection was done from May to June 2016. The tool used for this study was a pre-tested, self-administered questionnaire which was made available in dual languages (English and Malay). 
The questionnaire included components such as socio-demographic characteristics of the volunteers, awareness of their functions and roles, training, KOSPEN activity implementation, acceptance, and other related problems of the programme. Research assistants were trained to carry out the data collection. Written consent was obtained from all respondents who agreed to answer the questionnaire. The questionnaire was then given to the respondents to be answered on their own. The questionnaires were then collected and sent to the main office for data entry. Answers from the questionnaires were transferred to OMR forms and data was keyed in using SPSS software.

Ethical approval was obtained from Medical Research and Ethics Committee, Ministry of Health Malaysia (NMRR-16-524-30085). Factors associated with not performing health screening activities were based on the perception of the volunteers regarding several components such a management, training and monitoring. Management barriers include management of educational materials, funding, human resources and screening equipment. Training barriers include content and comprehensibility of the training module. Monitoring barriers include user friendliness of the health screening returns and the frequency of submitting returns (burdensome/not burdensome).

Data analysis was performed using Statistical Package for Social Sciences (SPSS) version 20. Descriptive statistics was used to illustrate the socio-demographic characteristics of the volunteers. 'Prevalence' was used to demonstrate the barriers in conducting health screening activities in the KOSPEN programme. Multiple logistic regression analysis was applied to determine factors associated with not performing KOSPEN screening activities by the volunteers. Univariate analysis (Simple logistic regression) was carried out by testing all the 14 potential predictor variables to screen for important independent variables. The variables with $p$-values $<0.25$ from univariate analysis (such as attend training, education material, screening equipment, content of training, comprehensibility of training, screening return and frequency return) were included in the preliminary final model for variable selection. Backward LR method was applied during variable selection. The variable selection is the process of "reducing the model" to get the best fit model by including all the candidate variables in the model and repeatedly removing the variables with the highest non-significant $\mathrm{p}$-value until the model contains only significant terms. Hence, the final model was created based on two variables significantly associated at the level of $p<0.05$ during the final steps of variables selection. Those variables were attended training and content of training. Multicollinearity and interaction were checked accordingly. The overall fitness was checked using a Hosmer Lameshow test, classification table and ROC (receiver operating characteristic) curve. The findings were presented as crude and adjusted odds ratios with their $95 \%$ confidence intervals.

\section{RESULTS}

A total of 700 volunteers were included in this study. The response rate of the volunteers who answered the questionnaire was $94.9 \%$. Table 1 describes the socio demographic characteristics of the respondents. Most of the volunteers were female $(65.7 \%)$ and $34.3 \%$ males. The greatest number of volunteers were aged 50-59 years of age (30.9\%), followed by those aged 40-49 (27.1\%). Education wise most of them had secondary education $(65.3 \%)$ and were employed $(55.7 \%$.). Majority of the volunteers were married $(80.4 \%)$.

Table 1 Socio demographic characteristics of KOSPEN volunteers $(n=700)$

\begin{tabular}{lrr}
\hline Socio-demographic characteristics & $\mathrm{n}$ & $\%$ \\
\hline Overall & 700 & \\
Sex & & \\
Male & 240 & 34.3 \\
Female & 460 & 65.7 \\
Age & & \\
18-29 & 93 & 13.3 \\
$30-39$ & 105 & 15.0 \\
$40-49$ & 190 & 27.1 \\
$50-59$ & 216 & 30.9 \\
$60+$ & 96 & 13.7 \\
Education & & \\
No formal education & 16 & 2.3 \\
Primary education & 87 & 12.4 \\
Secondary education & 457 & 65.3 \\
Tertiary education & 140 & 20.0 \\
Occupation & & \\
Employed & 390 & 55.7
\end{tabular}




\begin{tabular}{lcc} 
Unemployed/retiree/homemaker & 310 & 44.3 \\
Marital status & & \\
Single/Divorcee/widow/widower & 134 & 19.1 \\
Married & 563 & 80.4 \\
\hline
\end{tabular}

Table 2 shows the prevalence of volunteers who perceived management issues to be a barrier in conducting health screening activities. Most of the volunteers perceived funding $(47.2 \%)$ to be a barrier in conducting health screening activities followed by human resources $(21.4 \%)$. About $16 \%$ and $11 \%$ of the volunteers thought that screening equipment and educational materials were barriers in conducting health screening respectively.

Table 3 shows the prevalence of volunteers who perceived the training component to be a barrier in conducting health screening activities. Training component issues that were taken into account was the content in the training modules and its comprehensibility. Only $11.4 \%$ of the volunteers perceived the content of the module and comprehensibility of the module as a barrier in conducting health screening activities respectively.

Table 4 shows the prevalence of volunteers who perceived monitoring issues to be a barrier in conducting health screening activities. Monitoring issues include filling up health screening returns and the frequency of submitting those returns. Around $17.0 \%$ of volunteers found the frequency of submitting returns to be cumbersome while $7.8 \%$ felt doing the health screening returns itself to be a barrier in conducting health screening activities.

Table 5 shows factors associated with not performing health screening activities by the volunteers in the KOSPEN community. Logistic regression analysis showed significant association with volunteers who never attended training (cOR: $3.43,95 \%$ CI $2.13,5.52$ ) and volunteers who felt the content of the training module was inadequate (cOR: $3.07,95 \%$ CI $1.70,5.56)$ with not performing health screening activities. Volunteers who found it difficult to understand the training module (cOR: $3.12,95 \%$ CI $1.72,5.66)$ and who felt the screening returns were non-user friendly (cOR: $2,72,95 \% \mathrm{CI}$ $1.34,5.54)$ were more likely not to perform health screening activities. Contrarily, volunteers who had adequate screening equipment (cOR: $2.01,95 \% \mathrm{CI}$ $1.16,3.48$ ) were more likely not to perform health screening activities.

Through multivariate logistic regression, two factors were significantly associated with not performing health screening activities which are volunteers who never attended training and volunteers who felt the content of training was inadequate. We found that those volunteers who never attended training (aOR 2.79; 95\% CI:1.66, 4.67) were more likely not to conduct health screening activities and also those volunteers who felt the content of the training module was inadequate (aOR 2.693; 95\% CI: 1.46, 4.98) were more likely to not perform screening activities in the community.

Table 2 Prevalence of volunteers who perceived management issues to be a barrier in conducting health screening activities

\begin{tabular}{|c|c|c|c|c|c|c|c|c|}
\hline \multirow[t]{2}{*}{ Socio-demographic characteristics } & \multicolumn{2}{|c|}{ Educational materials } & \multicolumn{2}{|c|}{ Funding } & \multicolumn{2}{|c|}{ Human resources } & \multicolumn{2}{|c|}{ Screening equipment } \\
\hline & $\%$ & $95 \% \mathrm{CI}$ & $\%$ & $95 \% \mathrm{CI}$ & $\%$ & $95 \%$ CI & $\%$ & $95 \%$ CI \\
\hline Overall & $11.3 \%$ & $9.10,14.03$ & $47.2 \%$ & $43.41,50.98$ & $21.4 \%$ & $18.36,24.73$ & $16.1 \%$ & $13.53,19.15$ \\
\hline \multicolumn{9}{|l|}{ Sex } \\
\hline Male & $12.4 \%$ & $8.55,17.59$ & $49.5 \%$ & $42.80,56.26$ & $22.3 \%$ & $17.14,28.41$ & $19.0 \%$ & $14.20,24.85$ \\
\hline Female & $10.8 \%$ & $8.23,14.13$ & $45.9 \%$ & $41.37,50.58$ & $20.8 \%$ & $17.22,24.87$ & $14.7 \%$ & $11.67,18.23$ \\
\hline \multicolumn{9}{|l|}{ Age } \\
\hline $18-29$ & $7.7 \%$ & $3.71,15.27$ & $34.4 \%$ & $25.46,44.69$ & $18.0 \%$ & $11.33,27.33$ & $15.6 \%$ & $9.43,24.58$ \\
\hline $30-39$ & $13.5 \%$ & $8.04,21.90$ & $51.6 \%$ & $41.66,61.38$ & $24.0 \%$ & $16.48,33.47$ & $18.8 \%$ & $12.21,27.69$ \\
\hline $40-49$ & $14.5 \%$ & $10.08,20.49$ & $52.0 \%$ & $44.62,59.21$ & $24.6 \%$ & $18.81,31.43$ & $17.3 \%$ & $12.50,23.50$ \\
\hline $50-59$ & $9.0 \%$ & $5.75,13.82$ & $44.2 \%$ & 37.5151 .15 & $18.0 \%$ & $13.25,23.98$ & $13.2 \%$ & $9.13,18.71$ \\
\hline $60+$ & $11.5 \%$ & $6.08,20.80$ & $52.6 \%$ & $41.47,63.41$ & $22.5 \%$ & $14.65,32.93$ & $17.7 \%$ & $10.74,27.83$ \\
\hline \multicolumn{9}{|l|}{ Education } \\
\hline No formal education & $31.3 \%$ & $13.64,56.68$ & $31.3 \%$ & $13.65,56.66$ & $25.0 \%$ & $9.68,50.91$ & $18.8 \%$ & $6.13,44.91$ \\
\hline Primary education & $14.8 \%$ & $8.62,24.27$ & $49.4 \%$ & $38.73,60.09$ & $27.2 \%$ & $18.60,37.83$ & $14.8 \%$ & $8.59,24.36$ \\
\hline Secondary education & $9.9 \%$ & $7.39,13.22$ & $47.8 \%$ & $43.05,52.60$ & $20.8 \%$ & $17.15,25.05$ & $16.3 \%$ & $13.11,20.19$ \\
\hline Tertiary education & $11.2 \%$ & $6.86,17.76$ & $45.5 \%$ & $46.07,62.63$ & $18.7 \%$ & $12.95,26.12$ & $15.7 \%$ & $10.45,22.83$ \\
\hline \multicolumn{9}{|l|}{ Occupation } \\
\hline Employed & $9.6 \%$ & $6.92,13.11$ & $43.1 \%$ & $38.06,48.28$ & $18.2 \%$ & $14.52,, 22.58$ & $13.8 \%$ & $10.60,17.78$ \\
\hline Unemployed/retiree/homemaker & $13.5 \%$ & $10.01,17.95$ & $52.1 \%$ & $46.36,57.78$ & $25.1 \%$ & $20.38,30.46$ & $18.9 \%$ & $14.81,23.76$ \\
\hline \multicolumn{9}{|l|}{ Marital status } \\
\hline Single/Divorcee/widow/widower & $9.6 \%$ & $5.52,16.17$ & $45.6 \%$ & $37.14,54.33$ & 16.8 & $11.19,24.44$ & 16.9 & $11.32,24.56$ \\
\hline Married & 11.8 & $9.30,14.92$ & $47.6 \%$ & $43.30,51.80$ & 22.5 & $19.08,26.29$ & 16 & $13.09,19.31$ \\
\hline
\end{tabular}


Table 3 Prevalence of volunteers who perceived 'training component' issues to be a barrier in conducting health screening activities

\begin{tabular}{|c|c|c|c|c|}
\hline \multirow[t]{2}{*}{ Socio-demographic characteristics } & \multicolumn{2}{|c|}{ Module content } & \multicolumn{2}{|c|}{$\begin{array}{l}\text { Comprehensibility of } \\
\text { module }\end{array}$} \\
\hline & $\%$ & $95 \% \mathrm{CI}$ & $\%$ & $95 \% \mathrm{CI}$ \\
\hline Overall & $11.4 \%$ & $9.16,14.08$ & $11.4 \%$ & $9.15,14.10$ \\
\hline \multicolumn{5}{|l|}{ Sex } \\
\hline Male & $11.5 \%$ & $7.86,16.48$ & $10.6 \%$ & $7.07,15.53$ \\
\hline Female & $11.3 \%$ & $8.66,14.74$ & $11.8 \%$ & $9.05,15.23$ \\
\hline \multicolumn{5}{|l|}{ Age } \\
\hline $18-29$ & $12.5 \%$ & $7.03,21.25$ & $9.0 \%$ & $4.57,16.92$ \\
\hline $30-39$ & $8.5 \%$ & $4.31,16.12$ & $7.4 \%$ & $3.62,14.69$ \\
\hline $40-49$ & $10.6 \%$ & $6.91,15.97$ & $14.6 \%$ & $10.16,20.55$ \\
\hline $50-59$ & $11.4 \%$ & $7.61,16.73$ & $10.9 \%$ & $7.19,16.14$ \\
\hline $60+$ & $15.4 \%$ & $8.93,25.21$ & $12.8 \%$ & $7.03,22.24$ \\
\hline \multicolumn{5}{|l|}{ Education } \\
\hline No formal education & $12.5 \%$ & $3.18,38.29$ & $6.3 \%$ & $0.87,33.66$ \\
\hline Primary education & $12.3 \%$ & $6.77,21.46$ & $13.6 \%$ & $7.68,22.89$ \\
\hline Secondary education & $11.4 \%$ & $8.63,14.88$ & $11.4 \%$ & $8.63,14.87$ \\
\hline Tertiary education & $10.7 \%$ & $6.47,17.14$ & $10.7 \%$ & $6.50,17.08$ \\
\hline \multicolumn{5}{|l|}{ Occupation } \\
\hline Employed & $9.1 \%$ & $6.52,12.54$ & $9.1 \%$ & $6.51,12.56$ \\
\hline Unemployed/retiree/homemaker & $14.3 \%$ & $10.67,18.88$ & $14.3 \%$ & $10.64,18.91$ \\
\hline \multicolumn{5}{|l|}{ Marital status } \\
\hline Single/Divorcee/widow/widower & $10.7 \%$ & $6.26,17.56$ & $11.4 \%$ & $6.84,18.34$ \\
\hline Married & $11.6 \%$ & $9.14,14.70$ & $11.5 \%$ & $8.97,14.54$ \\
\hline
\end{tabular}

Table 4 Prevalence of volunteers who perceived 'monitoring' issues to be a barrier in conducting health screening activities

\begin{tabular}{lrrrr}
\hline Socio-demographic variables & \multicolumn{3}{c}{ Health Screening returns } & \multicolumn{2}{c}{$\begin{array}{c}\text { Frequency of submitting } \\
\text { returns }\end{array}$} \\
& $\%$ & $95 \%$ CI & \multicolumn{1}{c}{$\%$} & $95 \%$ CI \\
\hline Overall & 7.8 & $5.9,10.1$ & 17.0 & $14.2,20.1$ \\
Sex & & & & \\
Male & 6.7 & $4.0,11.0$ & 17.2 & $12.7,23.0$ \\
Female & 8.3 & $6.0,11.3$ & 16.8 & $13.6,20.7$ \\
Age & & & & \\
$18-29$ & $7.9 \%$ & $3.8,15.6$ & $15.6 \%$ & $9.4,24.6$ \\
$30-39$ & $7.4 \%$ & $3.6,14.8$ & $12.8 \%$ & $7.4,21.2$ \\
$40-49$ & $9.5 \%$ & $6.0,14.7$ & $17.3 \%$ & $12.4,23.6$ \\
$50-59$ & $5.8 \%$ & $3.2,10.1$ & $16.8 \%$ & $12.1,22.7$ \\
$60+$ & $9.0 \%$ & $4.4,17.6$ & $23.4 \%$ & $15.2,34.1$ \\
Education & & & & \\
No formal education & $0.0 \%$ & & $12.5 \%$ & $3.1,38.7$ \\
Primary education & $12.3 \%$ & $6.8,21.5$ & $12.3 \%$ & $6.8,21.5$ \\
Secondary education & $8.6 \%$ & $6.3,11.8$ & $16.5 \%$ & $13.3,20.4$ \\
Tertiary education & $3.1 \%$ & $1.2,8.0$ & $21.7 \%$ & $15.4,29.6$ \\
Occupation & & & & \\
Employed & $5.7 \%$ & $3.7,8.6$ & $17.3 \%$ & $13.7,21.6$ \\
Unemployed/retiree/homemaker & $10.4 \%$ & $7.4,14.6$ & $16.5 \%$ & $12.6,21.3$ \\
Marital status & & & & \\
Single/Divorcee/widow/widower & $8.9 \%$ & $5.0,15.3$ & $14.6 \%$ & $9.4,22.1$ \\
Married & $7.5 \%$ & $5.5,10.2$ & $17.6 \%$ & $14.6,21.2$ \\
\hline
\end{tabular}




\section{Community Health Workers}

Table 5 Factors associated with not performing health screening activities in the KOSPEN community

\begin{tabular}{|c|c|c|c|c|c|c|}
\hline \multirow[b]{2}{*}{ Variables } & \multicolumn{3}{|c|}{ Logistic Regression } & \multicolumn{3}{|c|}{ Multiple Logistic Regression } \\
\hline & $\begin{array}{c}\text { Crude } \\
\text { OR }\end{array}$ & $95 \% \mathrm{CI}$ & $\mathrm{p}$ value & $\begin{array}{c}\text { Adjusted } \\
\text { OR* }\end{array}$ & $95 \% \mathrm{CI}$ & $\mathrm{p}$ value \\
\hline \multicolumn{7}{|l|}{ Sex } \\
\hline Male & 1 & & & & & \\
\hline Female & 0.87 & $0.55,1.38$ & 0.566 & & & \\
\hline Age & 1.003 & $0.99,1.02$ & 0.713 & & & \\
\hline \multicolumn{7}{|l|}{ Education } \\
\hline No formal education & 1 & & & & & \\
\hline Primary education & 0.451 & $0.12,1.67$ & 0.234 & & & \\
\hline Secondary education & 0.507 & $0.16,1.64$ & 0.257 & & & \\
\hline Tertiary education & 0.353 & $0.10,1.25$ & 0.106 & & & \\
\hline \multicolumn{7}{|l|}{ Occupation } \\
\hline Employed & 1 & & & & & \\
\hline Unemployed/retiree/homemaker & 1.287 & $0.83,2.0$ & 0.260 & & & \\
\hline \multicolumn{7}{|l|}{ Marital status } \\
\hline Single/Divorcee/widow/widower & 1 & & & & & \\
\hline Married & 0.811 & $0.48,1.38$ & 0.440 & & & \\
\hline \multicolumn{7}{|l|}{ Training } \\
\hline Attended & 1 & & & 1 & & \\
\hline Never attend & 3.434 & $2.13,5.52$ & 0.000 & 2.785 & $1.66,4.67$ & 0.000 \\
\hline \multicolumn{7}{|l|}{ Educational materials } \\
\hline No & 0.668 & $0.35,1.28$ & 0.224 & & & \\
\hline Yes & 1 & & & & & \\
\hline \multicolumn{7}{|l|}{ Funding barrier } \\
\hline No & 1 & & & & & \\
\hline Yes & 1.088 & $0.7,1.70$ & 0.713 & & & \\
\hline \multicolumn{7}{|l|}{ Human resources } \\
\hline No & 1 & & & & & \\
\hline Yes barrier & 1.319 & $0.78,2.23$ & 0.303 & & & \\
\hline \multicolumn{7}{|l|}{ Screening equipment } \\
\hline Not adequate & 1 & & & & & \\
\hline Adequate & 2.008 & $1.16,3.48$ & 0.013 & & & \\
\hline Content of training & & & & 1 & & \\
\hline Not adequate & 3.069 & $1.70,5.56$ & 0.000 & 2.693 & $1.46,4.98$ & 0.002 \\
\hline Adequate & 1 & & & & & \\
\hline \multicolumn{7}{|l|}{$\begin{array}{l}\text { Comprehensibility of training } \\
\text { module }\end{array}$} \\
\hline Not easy to understand & 3.124 & $1.72,5.66$ & 0.000 & & & \\
\hline Easy to understand & 1 & & & & & \\
\hline \multicolumn{7}{|l|}{ Screening return } \\
\hline Non-user friendly & 2.721 & $1.34,5.54$ & 0.006 & & & \\
\hline User friendly & 1 & & & & & \\
\hline \multicolumn{7}{|l|}{ Frequency return } \\
\hline Burdensome & 1 & & & & & \\
\hline Not burdensome & 1.554 & $0.77,3.12$ & 0.216 & & & \\
\hline
\end{tabular}

*Backward LR Multiple Logistic regression was applied. Multicollinearity and interactions were checked and not found. Hosmer Lameshow test $\mathrm{P}$ value $=0.878$, Classification Table (overall correctly classified percentage $=$ $86.6 \%$ ) and ROC curve (area under ROC curve $=63.3 \%$ ) were accepted to check model fitness.

\section{DISCUSSION}

Health screening activities are important in early detection of NCDs and their risk factors. Volunteers and community health workers have been widely recognised to help in reducing the burden of NCDs in their communities. In order to function well as community volunteers, they need to have sufficient training and resources in place to facilitate their work. In our study, we found training as an 
important factor in determining if the volunteers would conduct health screening activities in the community. Volunteers who were not trained were not likely to perform screening activities. This could be due to lack of confidence since their knowledge is not adequate as community volunteers are usually lay persons with little or no medical training. ${ }^{10,11,12}$ One study reported that effective training increases their knowledge about cardiovascular diseases and with this they would be able to perform non-invasive screening in their communities which could be achieved in a short time with little resources. ${ }^{10,13,14}$ In a systematic review conducted by Marwa AbdelAll et al, eight studies were analysed for their effectiveness of training CHWs in terms of methods used and the training duration. It was reported that in all the studies, knowledge improved post training ${ }^{15}$. In a study by Kim Ozano et al., CHWs reported that multiple training sessions and refresher courses are needed to improve their performance ${ }^{16}$. This proves how important it is for the CHWs to be adequately trained prior to carrying out their duties. The KOSPEN volunteers however were required to attend a 2-day training course prior to being appointed but not all attended $(73.8 \%$ attended) the training that was provided ${ }^{8}$. Some studies also emphasised the need for refresher training especially in anthropometric measurements. ${ }^{10,11}$

In this study, $17 \%$ reported that the frequency of submitting returns to be cumbersome. A suggestion by CHWs interviewed in another study was to include verbal reporting to reduce the time spent on written returns. ${ }^{16}$

Apart from training, job aids such as equipment ${ }^{16}$ used to measure blood pressure, blood glucose, weight and height should be adequately available to these volunteers. $16.1 \%$ felt that inadequate screening equipment to be a barrier in conducting screening activities. Contrarily, in the univariate analysis, having adequate screening equipment were one of the factors associated with not performing health screening instead. Most studies reported the opposite where sufficient supplies increased the performance of CHWs. ${ }^{11,17}$

In another study, CHWs performance depended on an integration of supervision, incentives, training, accountability, communication, supplies and logistics. ${ }^{18}$ Therefore, we need foster a holistic approach to improve CHWs performance and to maintain their motivation as well.

In a qualitative study done in Swaziland, four changes were identified as possible ways to improve the performance of CHWs; i) an increase in incentives, ii) equipment and supplies that are more dependable, iii) more training and refresher courses, and iv) wider range of responsibilities. ${ }^{18}$ These findings are in line with the findings of this study where by conducting health screening activities was hampered due to funding $(47.2 \%)$, screening equipment (16.1\%) and training module content and comprehensibility (11.4\% respectively)

Another motivating factor that was reported by a number of studies was remuneration for these volunteers. Various studies showed that salary or remuneration given to the volunteers made them feel appreciated and encouraged them to continue serving their community ${ }^{19,20,21}$ and community volunteers were mostly dissatisfied with their salaries. ${ }^{22,23}$. However, Ojo et al, reported otherwise. ${ }^{24}$ However, this study did not explore this aspect in assessing the barriers faced by the volunteers in conducting the health screening activities.

\section{CONCLUSION}

This study provides findings about the importance of training for community health workers in conducting health screening activities in the KOSPEN programme. The findings showed that volunteers who never attended training and who felt the content of the training module was inadequate were more likely to not perform screening activities in the community. Several issues were identified by the volunteers; funding (47.2\%), module content and comprehensibility ( $11.4 \%$ respectively), submitting returns $(17 \%)$ and screening equipment $(16.1 \%)$ as a barrier in performing health screening activities. This gives us an insight of challenges faced by the volunteers in conducting health screening activities. Attendance of the training should be a pre-requisite to qualify as a volunteer. Improvement to the training module should done to increase comprehensibility of the modules among the volunteers. Effective training is also required to increase the volunteer's knowledge on NCD screening activities. Attendance of training should be made compulsory and improvement to the training module should done to increase comprehensibility. By acknowledging this, programme managers and stakeholders would be able to cater and solve the issues faced by these volunteers who are the main driving force in the KOSPEN programme.

\section{ACKNOWLEDGEMENT}

We would like to thank the Director General of Health Malaysia for his permission to publish this article.

Author Disclosures

The authors declare that they have no conflicting interests.

\section{REFERENCES}

1. Shin HR, Varghese C. WHO Western Pacific Regional Action Plan for the Prevention and Control of NCDs (20142020). Epidemiol Health. Available online at:

2014:e2014007. 
doi:10.4178/epih/e2014007.

2. Community Health Workers: World Health Organization (WHO). Available online at: https://www.who.int/workforcealliance/kn owledge/themes/community/en/.

3. Global Action Plan for the Prevention and Control of Non-Communicable Diseases 2013-2020; 2013.

4. Denman CA, Rosales C, Cornejo E, et al. Evaluation of the community-based chronic disease prevention program Meta Salud in Northern Mexico, 2011-2012. Prev Chronic Dis. 2014;11(9):1-9. doi:10.5888/pcd11.140218.

5. Alaofè H, Asaolu I, Ehiri J, et al. Community Health Workers in Diabetes Prevention and Management in Developing Countries. Ann Glob Heal. 2017; 83(3-4): 661-675. doi:10.1016/j.aogh.2017.10.009.

6. Gyawali B, Mishra SR, Neupane D, Vaidya A, Sandbæk A, Kallestrup P. Diabetes management training for female community health volunteers in Western Nepal: An implementation experience. BMC Public Health. 2018;18(1):1-10. doi:10.1186/s12889-018-5562-y.

7. Malaysia Ministry of Health (MOH). National Strategic Plan for NonCommunicable Disease ( NSP-NCD): Medium Term Strategic Plan to Further Strengthened the NCD Prevention and Control Program in Malaysia ( 2016-2025). 2016:28.

8. Selangor Health Department. Komuniti Sihat Pembina Negara. 2016:1-13.

9. Kuang Kuay L, Ismail H, Liana Ab Majid $\mathrm{N}$, et al. Community Empowers the Nation Programme (KOSPEN) 1166 PUBLIC HEALTH RESEARCH Factors Associated with Non-Participation in a Health Screening Programme and Its Barriers: Findings from the Community Empowers the Nation Programme (KOSPEN), Malaysia 2016.

10. Abrahams-Gessel S, Denman CA, Mendoza Montano C, et al. The Training and Field Work Experiences of Community Health Workers conducting non-invasive, population-based screening for Cardiovascular Disease in Four Communities in Low and Middle-Income Settings HHS Public Access. Glob Hear. 2015;10(1):45-

54.doi:10.1016/j.gheart.2014.12.008.

11. Geldsetzer P, De Neve JW, Boudreaux C, Bärnighausen T, Bossert TJ. Improving the performance of community health workers in Swaziland: Findings from a qualitative study. Hum Resour Health. 2017;15(1):1-9. doi:10.1186/s12960-017-0236-x.
12. Fatmah. Pengaruh Pelatihan pada Peningkatan Pengetahuan dan Keterampilan Teknis Penyuluhan Obesitas dan Hipertensi Kader Posbindu Kota Depok. Makara Seri Kesehat. 2013;17(2):49-54.

http://garuda.ristekdikti.go.id/documents/d etail/149532.

13. Gaziano TA, Abrahams-Gessel S, Denman CA, et al. An assessment of community health workers' ability to screen for cardiovascular disease risk with a simple, non-invasive risk assessment instrument in Bangladesh, Guatemala, Mexico, and South Africa: An observational study. Lancet Glob Heal. 2015;3(9):e556-e563. doi:10.1016/S2214-109X(15)00143-6.

14. Gaziano TA, Bertram M, Tollman SM, Hofman KJ. Hypertension education and adherence in South Africa: A costeffectiveness analysis of community health workers. BMC Public Health. 2014;14(1). doi:10.1186/1471-2458-14-240.

15. Abdel-All M, Putica B, Praveen D, Abimbola S, Joshi R. Effectiveness of community health worker training programmes for cardiovascular disease management in low-income and middleincome countries: A systematic review. BMJ Open. 2017;7(11):1-11. doi:10.1136/bmjopen-2016-015529.

16. Ozano K, Simkhada P, Thann K, Khatri R. Improving local health through community health workers in Cambodia: challenges and solutions. Hum Resour Health. 2018;16(1):2. doi:10.1186/s12960-0170262-8.

17. Chung MHL, Hazmi H, Cheah WL. Role performance of community health volunteers and its associated factors in Kuching district, Sarawak. J Environ Public Health. 2017;2017. doi:10.1155/2017/9610928.

18. Kok MC, Broerse JEW, Theobald S, Ormel $\mathrm{H}$, Dieleman M, Taegtmeyer $\mathrm{M}$. Performance of community health workers: Situating their intermediary position within complex adaptive health systems. Hum Resour Health. 2017;15(1):1-7. doi:10.1186/s12960-017-0234-z.

19. Ding H, Sun X, Chang W wei, Zhang L, Xu $X$ ping. A Comparison of Job Satisfaction of Community Health Workers before and after Local Comprehensive Medical Care Reform: A Typical Field Investigation in Central China. PLoS One. 2013;8(9):1-5. doi:10.1371/journal.pone.0073438.

20. Luo Z, Bai X, Min R, Tang C, Fang P. Factors influencing the work passion of Chinese community health service 
workers: An investigation in five provinces. BMC Fam Pract. 2014;15(1):19. doi:10.1186/1471-2296-15-77.

21. Glenton C, Colvin C, Carlsen B, Swartz A, Lewin S, Noyes J. A systematic review of barriers and facilitators to the implementation of lay health worker programmes for maternal and child health. cochrane database Syst Rev. 2013;(10):1-4. doi:10.1002/14651858.CD010414.pub2.w ww.cochranelibrary.com.

22. Hasan H, Aljunid SM. Job satisfaction among Community-Based Rehabilitation (CBR) workers in caring for disabled persons in the east coast region of Peninsular Malaysia. BMC Public Health. 2019;19(1):1-9. doi:10.1186/s12889-0196520-z.

23. George MS, Pant S, Devasenapathy N, Ghosh-Jerath S, Zodpey SP. Motivating and demotivating factors for community health workers: A qualitative study in urban slums of Delhi, India. WHO SouthEast Asia J public Heal. 2017;6(1):82-89. doi:10.4103/2224-3151.206170.

24. Ojo TT, Hawley NL, Desai MM, Akiteng AR, Guwatudde D, Schwartz JI. Exploring knowledge and attitudes toward noncommunicable diseases among village health teams in Eastern Uganda: A crosssectional study. BMC Public Health. 2017;17(1):1-11. doi:10.1186/s12889-0174954-8. 